\title{
ESTIMATIVAS DO NIVEL DE MORTALIDADE E DE ESPERANÇAS DE VIDA PARA O ESTADO DE SÃO PAULO, BRASIL, EM 1970
}

\author{
Jair L. F. SANTOS *
}

\section{RSPSP 140}

Santos, J. L. F. - Estimativas do nivel de mortalidade e de esperança de vida para o Estado de São Paulo, Brasil, em 1970. Rev. Saúde públ., S. Paulo, 6: 269-72, 1972.

Resumo: Resultados preliminares do Censo Demográfico de 1970, são utilizados para a determinação do nivel de mortalidade no Estado de São Paulo, Brasil. Através da teoria de populações estáveis $e$ de tábuas de vida modelo, encontrou -se tábuas de sobrevivência para os sexos mascuino e feminino. Acredita.se que estas tábuas refletem as condições de mor talidade vigentes nos períodos próximos a data censitária.

Unitermos: Mortalidade (estimativa); Tábuas de sobrevivência*; Estatística vi. tal*.

\section{N T O DUC AO}

Recentemente, o Ministério do Planejamento e Coordenação Geral, através do Centro Brasileiro de Estudos Demográficos ${ }^{1}$ publicou estimativas da esperança de vida ao nascer, para o Brasil como um todo, baseadas nos dados censitários de 1960 e 1970.

Embora seja de concenso geral que brevemente se terá publicado os resultados do Censo Demográfico de 1970, para o Estado de São Paulo, bem como os dados de óbitos para aquele ano - permitindo assim que se tenha estimativas da esperança de vida ao nascer para a população de nosso Estado pelos métodos mais adequados - é de grande interesse que se tenha de imediato uma ava. liação destas esperanças de vida. Embora de qualidade precária, qualquer estimativa que não envolva erros grosseiros será de grande valor para o homem de ciência, permitindo-lhe comparações $\mathbf{e}$ análises imediatas.

Objetiva este trabalho a determinação da esperança de vida ao nascer e do nível de mortalidade da população do Estado de São Paulo, segundo o sexo, para 1970.

\section{MATERIAL E METODOS}

Até a data da elaboração deste trabaIho, não se dispunha dos resultados cen. sitários para o Estado de São Paulo, em 1970. Recorreu-se às estimativas populacionais publicadas em 1967 (SANTOS ${ }^{4}$ ).

As estimativas populacionais por idade e sexo, citadas acima, constituem a fonte básica para as atuais estimativas. Através da distribuição etária acumulada para cada sexo e da taxa de crescimento de aproximadamente 2,9\% a.a., observada no periodo $1960 / 1970$, determinou-se o nível de mortalidade (e consequientemente as esperanças de vida ao nascer) através da teoria de população quase estáveis, desenvolvida por COALE ${ }^{2}$ e apresentada por Coale \& Demeny ${ }^{3}$.

\footnotetext{
* Do Centro de Estudos de Dinâmica Populacional da Faculdade de Saúde Pública da USP Av. Dr. Arnaldo, 715 - São Paulo, S.P. - Brasil.
} 
SANTOS, J. L. F. - Estimativas do nível de mortalidade e de esperança de vida para o Estado de Săo Paulo, Brasil em 1970. Rev. Saúde públ., S. Paulo, 6: 269-72, 1972.

Comparou-se, separadamente para cada sexo, as estruturas etárias da popula. ção do Estado com as populações estáveis de diversos níveis de mortalidade, para uma taxa de crescimento entre 2,5 e 3,0\% a.a., elegendo-se assim os niveis que melhor se ajustam à população estimada.

\section{R E S U L T A D O S}

Através das comparações citadas, encontrou.se para ambos os sexos o nível de mortalidade 19 , das Tábuas de vida modelo da família Sul. Na Tabela 1 po de-se verificar o grau de aproximação destas comparações.

TA B ELA 1

Distribuição etária acumulada para o Estado de São Paulo - 1970 e para as populações estáveis de nivel 19, segundo o sexo e taxas de crescimento especifjcadas

\begin{tabular}{|c|c|c|c|c|c|c|}
\hline \multirow[t]{3}{*}{ Sexo } & \multicolumn{3}{|c|}{ HOMENS } & \multicolumn{3}{|c|}{ MULHERES } \\
\hline & \multicolumn{2}{|c|}{$\begin{array}{l}\text { Populacoóes estáveis } \\
\text { taxas de crescimento }\end{array}$} & \multirow{2}{*}{$\begin{array}{c}\text { Estado de } \\
\text { Sao Paulo } \\
1970\end{array}$} & \multicolumn{2}{|c|}{$\begin{array}{l}\text { Populações esţ́veis } \\
\text { taxas de crescimento }\end{array}$} & \multirow{2}{*}{$\begin{array}{c}\text { Estado de } \\
\text { Såo Paulo } \\
1970\end{array}$} \\
\hline & $2,5 \%$ & $3,0 \%$ & & $2,5 \%$ & $3,0 \%$ & \\
\hline 5 & 0,1491 & 0,1663 & 0,1641 & 0,1458 & 0,1632 & 0,1622 \\
\hline 10 & 0,2775 & 0,3059 & 0,3061 & 0,2716 & 0,3005 & 0,3005 \\
\hline 15 & 0,3901 & 0,4254 & 0,4287 & 0,3820 & 0,4181 & 0,4187 \\
\hline 20 & 0,4889 & 0,5276 & 0,5281 & 0,4790 & 0,5188 & 0,5170 \\
\hline 25 & 0,5752 & 06147 & 0,6045 & 0,5640 & 0,6048 & 0,5940 \\
\hline 30 & 0,6506 & 0,6890 & 0,6697 & 0,6384 & 0,6783 & 0,6595 \\
\hline 35 & 0,7164 & 0,7520 & 0,7284 & 0,7034 & 0,7409 & 0,7197 \\
\hline 40 & 0,7735 & 0,8055 & 0,78115 & 0,7601 & 0,7941 & 0,7770 \\
\hline 45 & 0,8229 & 0,8506 & 0,8336 & 0,8094 & 0,8993 & 0,8315 \\
\hline 50 & 0,8653 & 0,8884 & 0,8797 & 0,8521 & 0,8775 & 0,8756 \\
\hline
\end{tabular}

Fontes: Para populaçóes estáveis: COALE \& DEMENY ${ }^{3}$

Para o Estado de Sáo Paulo: SANTOS 4

Observa-se que, para ambos os sexos, as estruturas etárias da população do Estado de São Paulo aproximam-se bastante das estruturas das populaçōes estáveis. A aproximação é extremamente nitida, nos grupos etários jovens, à taxa de $3.0 \%$ a.a. para, nos grupos etários mais velhos, vir a ser menos clara, mantendo-se porém ambas as estruturas etárias de São Paulo, sempre entre as estruturas estáveis com taxas de 2,5\% e 3,0\% a.a.

Por se tratar de estimativas temporárias que cederão, no devido tempo, o seu lugar a estimativas muito mais precisas, não nos demos ao trabalho de in- terpolar valores da estrutura etária entre as diferentes taxas ou entre os possiveis níveis.

As aproximações citadas são de tal ordem que possibilitam a afirmação de que dificilmente os verdadeiros valores da esperança de vida ao nascer estejam longe dos níveis escolhidos.

Baseados nas observações acima, podese escolher as tábuas de vida correspondentes às populações masculina e feminina do Estado, para 1970. As tábuas regionais modelo, escolhidas são: família Sul, nível 19, como publicadas por CoALE \& DemenY ${ }^{3}$ cujas cópias constam da Ta bela 2 . 
SANTOS, J. L. F. - Estimativas do nivel de mortalidade e de esperança de vida para o Bstado de Săo Paulo, Brasil em 1970. Rev. Saride públ., S. Paulo, 6: 269-72, 1972.

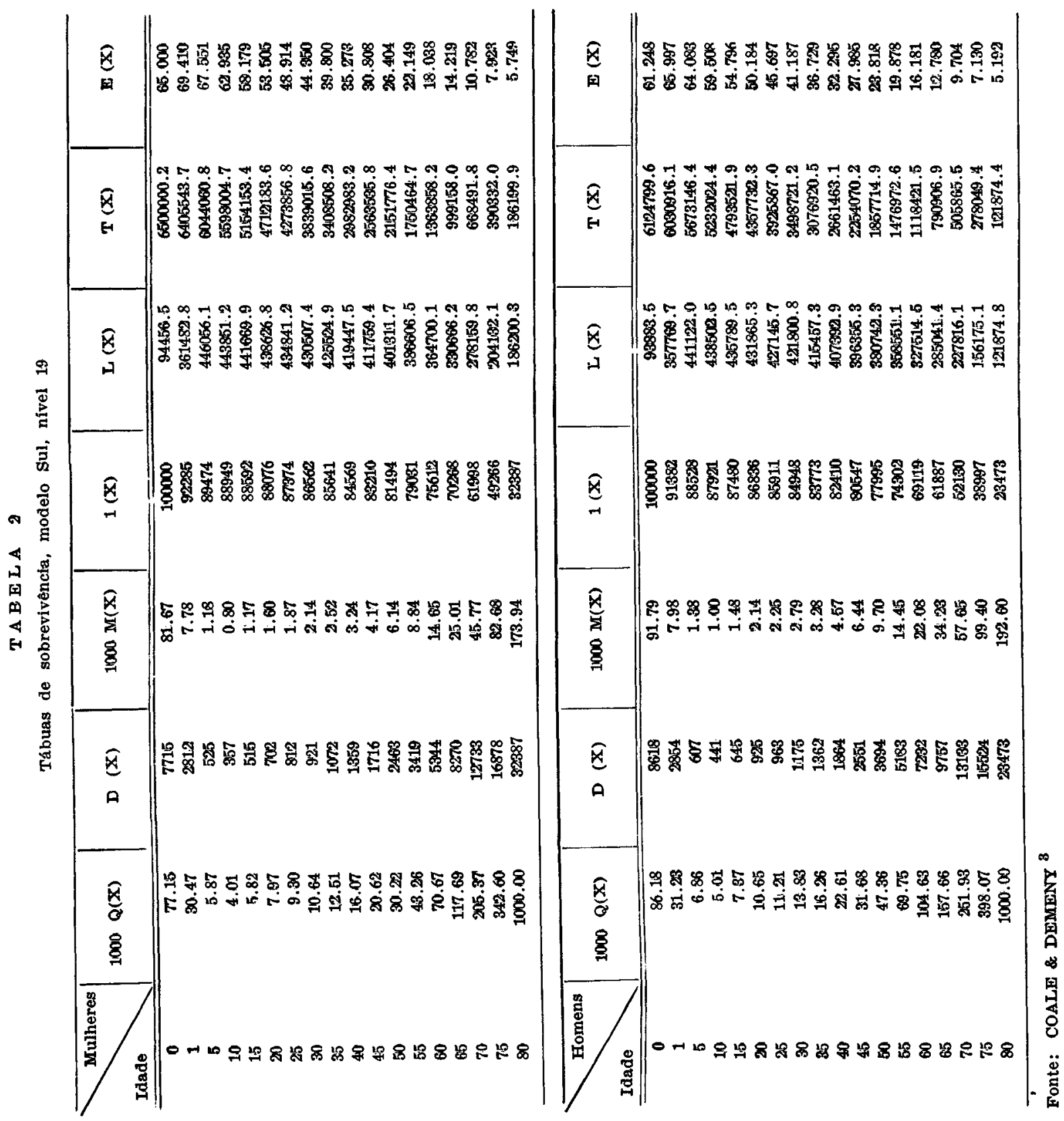


SANTOS, J. L. F. - Estimativas do nivel de mortalidade e de esperança de vida para o Estado de São Paulo, Brasil em 1970. Rev. Saúde públ., S. Paulo, 6: 269-72, 1972.

\section{CON CLUS OES}

Selecionados os niveis de mortalidade para cada sexo, verificou-se que as esperanças de vida ao nascer, estimadas para o Estado de São Paulo, em 1970, são:

\section{5,0 anos para o sexo feminino}

61,2 anos para o sexo masculino.

As estimativas para o Brasil 1, apontam:

\section{1,10 para o sexo feminino}

$$
\text { 57,01 para o sexo masculino, }
$$

o que colocaria nosso Estado com uma esperança de vida ao nascer cerca de 4 anos maior que a do Brasil, para ambos os sexos.

No caso das estimativas para o Estado de São Paulo, mesmo tendo-se subestimado ou superestimado o nível de mortalidade por uma unidade, isto acarretaria um erro nas estimativas da esperan. ça de vida ao nascer de cerca de $3,0 \%$.

\section{RSPSP-140}

Santos, J. L. F. - [Estimatives of mortality rate and life expectance for the S. Paulo, State, Brazil, in 1970. Rev. Saúde públ., S. Paulo, 6: 269-72, 1972.

Summary: Preliminary results of the 1970 Demographic Census in Brazil lead the author to determining the mortality level for the State of São Paulo, Brazil. Life Tables for males and females were found through stable population theory and model life tables. It is believed that those tables reflect mortality conditions of the State of S. Paulo during the perioa close to tne c'ensus date.

UnITERms: Mortality rate*; Life tables*; Vital statistics*.

REFER@NCIAS BIBLIOGRAFI,CAS

1. BRASIL, Ministério do Planejamento e Coordenação Geral - Estimativa para - Brasil, da vida media ao nascer au. rante o periodo $1960 / 1970$ a partir de razões de sobrevivência intercensitárias. Rio de Janeiro, 1971.

2. COALE, A. J. - Estimates of various de. mographic measures, through the quasistable age distribution. In: ANNUAL CONFERENCE OF THE MILBANK MEMORIAL FUND, New York, 1962. New York, Milbank Memorial Fund, 1963. p. 175-93.

3. COALE, A. S. \& DEMENY, P. - Regional model life tables an stable populations. Princeton, N. J., Princeton Univ. Press, 1966.

4. Santos, J. L. F. - Projeção da popula. ção em idade escolar e das necessidades para o seu atendimento, no Estado de São Paulo, 1965-1980. Rev. Saúde públ., S. Paulo, 1: 59-78, 1967.

Aprovado para publisagão em 10-7.1972

Recebido para publicação em 26.7.1972 